\title{
Risk factors and complications of small for gestational age
}

\author{
Qiang Liu', Hui Yang'2, \\ Xuemei Sun ${ }^{3}$, Guimei $\mathrm{Li}^{4}$
}

\begin{abstract}
Objective: The objective of this study was to find out the maternal risk factors and perinatal complications in small for gestational age (SGA) newborns.

Methods: A total of 181 SGA cases and 1299 cases of appropriate for gestational age (AGA) with the same gestational age between January 2015 and December 2016 were enrolled in Linyi People's Hospital, China. The risk factors were analyzed and the frequencies of perinatal complications were compared between the two groups.

Results: The frequencies of maternal risk factors such as pregnancy-induced hypertension, abnormal placenta and twins in the SGA group were significantly higher than that in the AGA group $(P<0.05)$. The incidence of hyperbilirubinemia and hypoglycemia in the perinatal period was also higher in the SGA newborns group $(P<0.05)$, while there were no significant differences in the incidence of pneumonia, apnea, septicemia, intracranial hemorrhage, neonatal asphyxia, congenital malformations, hypoxicischemic encephalopathy, respiratory distress syndrome and necrotizing enterocolitis between the two groups.

Conclusions: SGAcan cause perinatal complications including neonatal hypoglycemia and hyperbilirubinemia. It is necessary to strengthen the perinatal monitoring and antenatal care to reduce SGA and the perinatal complications of SGA.
\end{abstract}

KEYWORDS: Complications, Risk factors, Small for gestational age.

doi: https://doi.org/10.12669/pjms.35.5.253

How to cite this:

Liu Q Yang H, Sun X, Li G. Risk factors and complications of small for gestational age. Pak J Med Sci. 2019;35(5):1199-1203. doi: https://doi.org/10.12669/pjms.35.5.253

This is an Open Access article distributed under the terms of the Creative Commons Attribution License (http://creativecommons.org/licenses/by/3.0), which permits unrestricted use, distribution, and reproduction in any medium, provided the original work is properly cited.

1. Dr. Qiang Liu,

Department of Newborn,

2. Dr. Hui Yang,

Department of Anesthesiology,

3. Dr. Xuemei Sun,

Department of Newborn,

4. Dr. Guimei Li,

Department of Pediatrics,

Shandong Provincial Hospital Affiliated to Shandong University,

Shandong University, Jinan, Shandong, 250021, China.

1-3: Linyi People's Hospital, Linyi, Shandong, 276003, China.

Correspondence:

Dr. Guimei Li,

Department of Pediatrics,

Shandong Provincial Hospital Affiliated to Shandong University

324 Jingwuweiqi Road, Jinan,

Shandong, 250021, China.

E-mail: liguimei2013@126.com

liuqiangsd12@163.com

* Received for Publication:

December 24, 2018

* Revision Received:

* Revision Accepted:
June 10, 2019

June 15, 2019

\section{INTRODUCTION}

Small for gestational age infant (SGA) was defined by the WHO in 1995 as the infant with birth weight below the 10th percentile of mean body weight of the infants of same gestational age and same gender. ${ }^{1}$ In 2001, the World SGA Development Conference announced that SGA refers to birth weight and/ or body length below averagely two standard deviations ( $\leq-2 \mathrm{~s})$ of same gestational age, about the third percentile of body weight and/or body length of same gestational age. ${ }^{2}$

SGA has higher mortality than infants with normal birth weight, and is one of the major causes of perinatal death. ${ }^{3,4}$ SGA not only threatens the growth and development of fetus in the uterus, but also affects physical and mental development in childhood and adolescence, ${ }^{5,6}$ causing learning 
difficulties, language barriers and cognitive and behavioral defects ${ }^{7-9}$, and even increasing the incidence of autism. ${ }^{10} \mathrm{SGA}$ is closely related to some important diseases in adulthood. ${ }^{11}$ The prevalence of SGA births has been reported to be $8.6 \%-11.4 \%$ in several countries, ${ }^{12}$ while in China, the overall prevalence of SGA is estimated to be $8 \%-13 \%$. $^{13}$

Premature infants, term infants and post term infants may develop SGA. The causes are complex, and many studies always aimed at a single risk factor for research, such as mother's age, socioeconomic status and education, body mass index and obesity, prenatal diet and nutrition, diseases in pregnancy, smoking, placental conditions, etc. Pregnancy-induced hypertension is one of the main causes of SGA. ${ }^{14}$ It is a common complication in pregnancy and is the leading cause of maternal and perinatal fetal death. Pregnancyinduced hypertension affects fetal development in the uterus by impairing uterine artery, myometrial spiral artery, basilar artery, placental blood vessels and umbilical artery. ${ }^{15}$ It should be noted that elderly pregnant women are prone to pregnancyinduced hypertension and other complications, leading to occurrence of SGA. ${ }^{16}$ SGA infants have many perinatal complications, commonly preterm birth NEC (necrotizing enterocolitis) and adverse perinatal outcome, and is the second major cause for perinatal diseases and death, following premature birth, but there are still differences between the research findings, such as hypoglycemia. ${ }^{17,18} \mathrm{In}$ order to find out the risk factors and complications of SGA, SGA and AGA cases were retrospectively collected from a tertiary-care hospital in China and analyzed in this study.

\section{METHODS}

This was a retrospective case-control study, which was approved by the Ethics Committee of Linyi People's Hospital. A total of 181 SGA and 1299 AGA cases (controls) from January 2015 to December 2016 were enrolled in Linyi People's Hospital, China. Sampling was not applied. The

Table-I: Basic description.

\begin{tabular}{lccc}
\hline & Cases $(n=181)$ & Controls $(n=1299)$ & P-value \\
\hline Gestational Age(weeks) & $36.24(2.252)$ & $36.6(3.170)$ & $<0.001$ \\
Birth weight(g) & $1926.35(590.538)$ & $2875.67(793.309)$ & $<0.001$ \\
Male, $n$ & $85(46.96 \%)$ & $823(63.36 \%)$ & $<0.001$ \\
Risk Factors & & & \\
Twins, $n$ & $33(18.23 \%)$ & $135(10.39 \%)$ & 0.002 \\
Premature rupture of membrane, $n$ & $16(8.84 \%)$ & $174(13.39 \%)$ & 0.086 \\
Abnormality of amniotic fluid, $n$ & $57(31.49 \%)$ & $370(28.48 \%)$ & 0.403 \\
Abnormality of umbilical cord, $n$ & $217(14.92 \%)$ & $1082(16.71 \%)$ & 0.544 \\
Abnormality of placenta, $n$ & $25(13.81 \%)$ & $118(9.08 \%)$ & 0.044 \\
Abnormal labor, $n$ & $20(11.05 \%)$ & $170(13.09 \%)$ & 0.443 \\
Pregnancy-induced hypertension syndrome, $n$ & $38(20.99 \%)$ & $76(5.85 \%)$ & $<0.001$ \\
Intrahepatic cholestasis of pregnancy, $n$ & $16(8.84 \%)$ & $95(7.31 \%)$ & 0.465 \\
Anemia, $n$ & $9(4.97 \%)$ & $51(3.93 \%)$ & 0.504 \\
Smoking or Passive Smoking, $n$ & $23(12.71 \%)$ & $151(11.62 \%)$ & 0.672 \\
Advanced paternal age, $n$ & $7(3.87 \%)$ & $71(5.47 \%)$ & 0.367 \\
Perinatal complication & & & \\
Asphyxia, $n$ & & $339(26.10 \%)$ & 0.320 \\
Congenital malformation, $n$ & $41(22.65 \%)$ & $162(12.47 \%)$ & 0.474 \\
Hypoglycemia, $n$ & $26(14.36 \%)$ & $148(11.39 \%)$ & $<0.001$ \\
Hypoxie-ischemic encephalopathy, $n$ & $39(21.55 \%)$ & $381(29.33 \%)$ & 0.276 \\
Neonatal respiratory distress syndrome, $n$ & $46(25.41 \%)$ & $243(18.71 \%)$ & 0.382 \\
Neonatal necrotizing enterocolitis, $n$ & $29(16.02 \%)$ & $39(3.00 \%)$ & 0.308 \\
Pneumonia, $n$ & $8(4.42 \%)$ & $528(40.65 \%)$ & 0.516 \\
Hyperbilirubinemia, $n$ & $69(38.12 \%)$ & $316(24.31 \%)$ & 0.001 \\
Apnea, $n$ & $66(36.34 \%)$ & $41(3.16 \%)$ & 0.775 \\
Sepsis, $n$ & $5(2.76 \%)$ & $59(4.54 \%)$ & 0.270 \\
Intracranial Haemorrhage, $n$ & $5(2.76 \%)$ & $225(17.32 \%)$ & 0.119 \\
\hline NP-value was gen & $23(12.71 \%)$ & & \\
\hline
\end{tabular}

${ }^{*}$ P-value was generated from t-test or Pearson chi-square test. 
Table-II: Risk factors for SGA using logistic regression model with multiple covariates.

\begin{tabular}{lccc}
\hline & OR & $95 \%$ CI & $P$ \\
\hline Gestational Age (weeks) & 0.978 & $(0.923,1.036)$ & 0.444 \\
Gender (Male) & 0.537 & $(0.390,0.741)$ & $<0.001$ \\
Twins & 1.946 & $(1.233,3.073)$ & 0.004 \\
Premature rupture of Membrane & 0.624 & $(0.356,1.093)$ & 0.099 \\
Abnormality of placenta & 1.626 & $(0.997,2.653)$ & 0.051 \\
Pregnancy-induced -Hypertension syndrome & 3.923 & $(2.533,6.077)$ & $<0.001$ \\
C-statistic=0.698. & & & \\
\hline
\end{tabular}

SGA cases accounted for $12.23 \%(181 / 1480)$ of all subjects, consistent with the overall prevalence of China $(8 \%-13 \%)$. The sample size of SGA was consistent with previous studies. ${ }^{19}$ The diagnostic criteria for SGA referred to the neonatal normal weight standard of different gestational ages, ${ }^{20}$ as below the 10th percentile of birth weight of the overall population of same gestational age.

Clinical information: Information including pregnant mother's general demographic characteristics, perinatal complications including neonatal asphyxia, congenital malformations, hypoglycemia, neonatal hypoxic-ischemic encephalopathy, neonatal respiratory distress syndrome, neonatal necrotizing enterocolitis, neonatal pneumonia, neonatal hyperbilirubinemia, neonatal apnea, neonatal sepsis and neonatal intracranial hemorrhage, and physiological indicators including gestational age, birth weight and gender was collected by reviewing the electronic neonatal and obstetric records with complete information.

Statistical analysis: Patients' characteristics were summarized by mean \pm SD for continuous variables and frequency for categorical variables. Independent two-sample t-test and chi-square test were used for group comparisons. Normal distribution assumptions were examined using Q-Q plots. SGA risk factors were identified by logistic regression. The risk factors in univariate analysis ( $p$-value $<0.1$ ) were included. Gestational age and gender were also included. The odds ratio of SGA for each factor was calculated. Logistic regression was also used to evaluate SGA as a risk factor for different perinatal complications. The predictive abilities of models were reasonable with C-statistics presented. All statistical tests were conducted at a two-sided 5\% significance level using SPSS 21.0.

\section{RESULTS}

SGA occurred more frequently at low gestational age $(\mathrm{P}<0.001)$, low birth weight $(\mathrm{P}<0.001)$, gender (female) $(\mathrm{P}<0.001)$, twins $(\mathrm{P}=0.002)$, and the differences were statistically significant $(\mathrm{P}<0.001)$. Compared with the control group, the mothers of the SGA group were more likely to have placental abnormalities in pregnancy $(\mathrm{P}=0.044)$ and $\mathrm{PIH}$ $(\mathrm{P}<0.001)$. The frequencies of hypoglycemia $(\mathrm{P}<0.001)$ and of hyperbilirubinemia $(\mathrm{P}<0.001)$ were significantly higher in the SGA group than in the control group, while there were no significant differences in the incidence of other examined complications. Table-I

Gender ( $p$-value $<0.001)$, Twins ( $p$-value $=0.004)$ and Pregnancy-induced hypertension ( $\mathrm{p}$-value $<0.001)$ ) were the risk factors of SGA. Table-II. Logistic regression model found that SGA was risk factor of perinatal complications: hypoglycemia ( $p$-value $<0.001)$ and hyperbilirubinemia ( $\mathrm{p}$-value $<0.001)$. Table-III

\section{DISCUSSION}

The causes and pathogenesis of SGA remain unclear and have not previously been well characterised. This study analyzed the risk factors

Table-III: Effect of SGA on the Perinatal Complications.

\begin{tabular}{lcccc}
\hline & \multicolumn{2}{c}{ Neonatal hypoglycemia } & \multicolumn{2}{c}{ Neonatal Hyperbilirubinemia } \\
\hline & OR $(95 \% \mathrm{CI})$ & $P$ & OR $(95 \% \mathrm{CI})$ & $P$ \\
\hline SGA & $2.081(1.393,3.111)$ & $<0.001$ & $0.530(0.368,0.763)$ & 0.001 \\
Gestational -Age & $0.853(0.812,0.896)$ & $<0.001$ & $0.871(0.840,0.903)$ & $<0.001$ \\
Gender (Male) & $0.844(0.612,1.163)$ & 0.299 & $0.996(0.794,1.250)$ & 0.975 \\
\hline
\end{tabular}

Each column represents one logistic model with the perinatal complication as the outcome.

The C-statistic for each model are 0.677, 0.605, respectively. 
and complications of SGA with data collected from a tertiary-care hospital in China.

Although the identified risk factors of SGA varied among studies, it is mostly believed that the risk factors include obstetric and fetal factors. This study showed that pregnancyinduced hypertension of pregnant mother, twins, female infant are common causes of SGA. Consistent with previous reports, ${ }^{14}$ pregnancyinduced hypertension remained to be a major cause of SGA, which is known to affect fetal development in the uterus. Meanwhile, the multiple birth-caused SGA were likely due to the unbalanced placental blood supply or interfetal blood transmission, which further lead to insufficient oxygen or nutrient supply. Unlike previous observation ${ }^{21}$, in this study it was found that female infant was a cause of SGA and thus further validation is needed. Studies have found that pregnancy with severe anemia ${ }^{22}$, smoking or passive smoking of mothers ${ }^{23,24}$ are risk factors of SGA, which however were not confirmed in this study. That might be due to the difference in the studied population as it has been reported that ethnicity was a factor associated with SGA, ${ }^{25}$ and in this study, all subjects were Chinese.

It is known that SGA newborns have high rates of morbidity and mortality and may also suffer from malnutrition and life-long complications. In addition, SGA often causes a variety of perinatal complications. ${ }^{26}$ In this study, it was found that hypoglycemia and hyperbilirubinemia were perinatal complications of SGA. SGA newborns might have a condition with low hepatic glycogen storage, high glucose consuming due to disease stress, and/or unstable glucose metabolism that could result in hypoglycemia. Therefore, although the hypoglycemia could improve along with growth, it is important to conduct close monitoring of blood glucose level for the newborns to avoid hypoglycemia-induced impairments. The SGA fetus might embedded in a relatively anoxic environment, and the consequent conditions such as compensatory increase of the red blood cell number and/or acidosis might lead to hyperbilirubinemia. ${ }^{27,28}$

\section{CONCLUSION}

In conclusion, SGA is the result of multifactor interaction and it can cause perinatal complications including neonatal hypoglycemia and hyperbilirubinemia.
Grant Support \& Financial Disclosures: None.

Conflicts of Interest: None.

\section{REFERENCES}

1. de Onis M, Habicht JP. Anthropometric reference data for international use: recommendations from a World Health Organization Expert Committee. Am J Clin Nutr. 1996;64(4):650-658. doi: 10.1093/ajcn/64.4.650

2. Lee PA, Chernausek SD, Hokken-Koelega AC, Czernichow P, International Small for Gestational Age Advisory Board. International Small for Gestational Age Advisory Board consensus development conference statement: management of short children born small for gestational age, April 24-October 1, 2001. Pediatrics. 2003;111(6 Pt 1):1253-1261.

3. Katz J, Lee AC, Kozuki N, Lawn JE, Cousens S, Blencowe $\mathrm{H}$, et al. Mortality risk in preterm and small-for-gestationalage infants in low-income and middle-income countries: a pooled country analysis. Lancet. 2013;382(9890):417-425. doi: 0.1016/S0140-6736(13)60993-9

4. Ota E, Ganchimeg T, Morisaki N, Vogel JP, Pileggi C, Ortiz-Panozo E, et al. Risk factors and adverse perinatal outcomes among term and preterm infants born small-forgestational-age: secondary analyses of the WHO MultiCountry Survey on Maternal and Newborn Health. PLoS One. 2014;9(8):e105155. doi: 10.1371/journal.pone.0105155

5. Ochiai M, Nakayama H, Sato K, Iida K, Hikino S, Ohga S, et al. Head circumference and long-term outcome in small-forgestational age infants. J Perinat Med. 2008;36(4):341-347. doi: 10.1515/JPM.2008.042

6. Shim YS, Park HK, Yang S, Hwang IT. Age at menarche and adult height in girls born small for gestational age. Ann Pediatr Endocrinol Metab. 2013;18(2):76-80. doi: 10.6065/ apem.2013.18.2.76

7. Karagianni P, Kyriakidou M, Mitsiakos G, Chatzioanidis H, Koumbaras E, Evangeliou A, et al. Neurological outcome in preterm small for gestational age infants compared to appropriate for gestational age preterm at the age of 18 months: a prospective study. J Child Neurol. 2010;25(2):165170. doi: $10.1177 / 0883073809333538$

8. Savchev S, Sanz-Cortes M, Cruz-Martinez R, Arranz A, Botet F, Gratacos E, et al. Neurodevelopmental outcome of fullterm small-for-gestational-age infants with normal placental function. Ultrasound Obstet Gynecol. 2013;42(2):201-206. doi: $10.1002 /$ uog.12391

9. Christian P, Murray-Kolb LE, Tielsch JM, Katz J, LeClerq SC, Khatry SK. Associations between preterm birth, smallfor-gestational age, and neonatal morbidity and cognitive function among school-age children in Nepal. BMC Pediatr. 2014;14:58. doi: 10.1186/1471-2431-14-58

10. Lampi KM, Lehtonen L, Tran PL, Suominen A, Lehti V, Banerjee PN, et al. Risk of autism spectrum disorders in low birth weight and small for gestational age infants. J Pediatr. 2012;161(5):830-836. doi: 10.1016/j.jpeds.2012.04.058

11. Risnes KR, Vatten LJ, Baker JL, Jameson K, Sovio U, Kajantie E, et al. Birthweight and mortality in adulthood: a systematic review and meta-analysis. Int J Epidemiol. 2011;40(3):647661. doi: 10.1093/ije/dyq267

12. Nam HK, Lee KH. Small for gestational age and obesity: epidemiology and general risks. Ann Pediatr Endocrinol Metab. 2018;23(1):9-13. doi: 10.6065/apem.2018.23.1.9

13. Yao F, Miao H, Li B, Wu Y, Zhao Q. New birthweight percentiles by sex and gestational age in Southern China and its comparison with the INTERGROWTH-21st Standard. Sci Rep. 2018;8(1):7567. doi: 10.1038/s41598-018-25744-7 
14. von Dadelszen P, Magee LA, Taylor EL, Muir JC, Stewart $\mathrm{SD}$, Sherman $\mathrm{P}$, et al. Maternal hypertension and neonatal outcome among small for gestational age infants. Obstet Gynecol. 2005;106(2):335-339. doi: 10.1097/01. AOG.0000171121.31564.14

15. Catov JM, Nohr EA, Olsen J, Ness RB. Chronic hypertension related to risk for preterm and term small for gestational age births. Obstet Gynecol. 2008;112(2 Pt 1):290-296. doi: 10.1097/AOG.0b013e31817f589b

16. Allen VM, Joseph K, Murphy KE, Magee LA, Ohlsson A. The effect of hypertensive disorders in pregnancy on small for gestational age and stillbirth: a population based study. BMC Pregnancy Childbirth. 2004;4(1):17. doi: 10.1186/14712393-4-17

17. Narchi H, Skinner A, Williams B. Small for gestational age neonates--are we missing some by only using standard population growth standards and does it matter? J Matern Fetal Neonatal Med. 2010;23(1):48-54. doi: 10.3109/14767050903067352

18. Tsai LY, Chen YL, Tsou KI, Mu SC, Taiwan Premature Infant Developmental Collaborative Study G. The impact of small-for-gestational-age on neonatal outcome among very-low-birth-weight infants. Pediatr Neonatol. 2015;56(2):101-107. doi: 10.1016/j.pedneo.2014.07.007

19. Ruwanpathirana T, Fernando DN. Risk factors for 'small for gestational age babies'. Indian J Pediatr. 2014;81(10):10001004. doi: 10.1007/s12098-014-1382-y

20. Zhu L, Zhang R, Zhang S, Shi W, Yan W, Wang X, et al Chinese neonatal birth weight curve for different gestational age. Zhonghua Er Ke Za Zhi. 2015;53(2):97-103.

21. Muhihi A, Sudfeld CR, Smith ER, Noor RA, Mshamu S, Briegleb C, et al. Risk factors for small-for-gestational-age and preterm births among 19,269 Tanzanian newborns. BMC Pregnancy Childbirth. 2016;16:110. doi: 10.1186/ s12884-016-0900-5

22. Faraci M, Renda E, Monte S, Di Prima FA, Valenti O, De Domenico R, et al. Fetal growth restriction: current perspectives. J Prenat Med. 2011;5(2):31-33.
23. McCowan LM, Dekker GA, Chan E, Stewart A, Chappell LC, Hunter M, et al. Spontaneous preterm birth and small for gestational age infants in women who stop smoking early in pregnancy: prospective cohort study. BMJ. 2009;338:b1081. doi: 10.1136/bmj.b1081

24. Voigt M, Briese V, Jorch G, Henrich W, Schneider KT, Straube $\mathrm{S}$. The influence of smoking during pregnancy on fetal growth. Considering daily cigarette consumption and the SGA rate according to length of gestation. Z Geburtshilfe Neonatol. 2009;213(5):194-200. doi: 10.1055/ s-0029-1214405

25. McCowan L, Horgan RP. Risk factors for small for gestational age infants. Best Pract Res Clin Obstet Gynaecol. 2009;23(6):779-793. doi: 10.1016/j.bpobgyn.2009.06.003

26. Pallotto EK, Kilbride HW. Perinatal outcome and later implications of intrauterine growth restriction. Clin Obstet Gynecol. 2006;49(2):257-269.

27. Troger B, Muller T, Faust K, Bendiks M, Bohlmann MK, Thonnissen $S$, et al. Intrauterine growth restriction and the innate immune system in preterm infants of $\leq 32$ weeks gestation. Neonatology. 2013;103(3):199-204. doi: $10.1159 / 000343260$

28. Holzmann $M$, Cnattingius S, Nordstrom L. Lactate production as a response to intrapartum hypoxia in the growth-restricted fetus. BJOG. 2012;119(10):1265-1269. doi: $10.1111 / \mathrm{j} .1471-0528.2012 .03432 . x$

\section{Author`s Contribution:}

GL conceived, designed and did statistical analysis \& editing of manuscript.

QL, HY and XF did data collection and manuscript writing.

QL and GL did review and final approval of manuscript. 